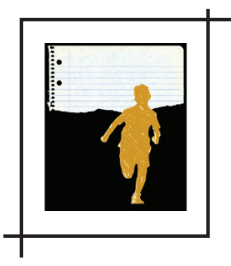

\title{
WALTER BENJAMIN, INFÂNCIIAS E A PEDAGOGIA SOCIAL: EXPERIÊNCIAS SOCIOPEDAGÓGICAS DESENVOLVIDAS NOS CENTROS DE EDUCAÇÃO INFANTIL DO BOMPAR ${ }^{1}$
}

\author{
Leandro Alves Lopes* \\ Maria Stela Santos Graciani**
}

Resumo: A Pedagogia Social vem sistematizando práticas libertárias que contribuem para a constituição de uma cultura democrática, gerando novas relações societárias. Mas, para isso, são necessários processos formativos emancipadores desde o nascimento, o que pressupõe desconstruir concepções adultocêntricas e compreender que os bebês e as crianças são sujeitos históricos, detentores de direitos, que produzem cultura e saberes. Logo, este artigo refletiu parte das experiências sociopedagógicas desenvolvidas em 18 unidades de educação infantil. Como técnicas metodológicas utilizaram-se análise de documentos institucionais e legislações, observação e roda de conversa. Os dados coletados foram analisados a partir das contribuições de Walter Benjamin. Um dos resultados é a necessidade de os educadores sociais beberem do "novo" que brota na educação infantil para que possam planejar práticas sociopedagógicas, socioculturais e sociopolíticas que considerem as infâncias e os dramas dos territórios.

Palavras-chave: Experiência. Pedagogia Social. Walter Benjamin. Bompar. Infância.

1 - Este trabalho faz parte do conjunto de pesquisas produzidas pelo Grupo de Pesquisa em Pedagogia Social da Universidade Presbiteriana Mackenzie (UPM). Destaca-se que parte do material deste artigo compôs a dissertação de mestrado do autor, com bolsa do Fundo Mackenzie de Pesquisa (MackPesquisa) e da Coordenação de Aperfeiçoamento de Pessoal de Nivel Superior (Capes), sob orientação do professor Dr. João Clemente de Souza Neto e coorientação do professor Dr. Bernd Fichtner.

* Mestre em Educação, Arte e História da Cultura pela Universidade Presbiteriana Mackenzie, membro do Grupo de Pesquisa em Pedagogia Social. Orientador Pedagógico Pastoral do Centro Social Nossa Senhora do Bom Parto. Coordenador da Pastoral do Menor da Região Episcopal Belém/Arquidiocese de São Paulo e assessor da Pastoral do Menor do Estado de São Paulo triênio 2018/2020. E-mail:|44eandro.alps1@gmail.com

** Doutora em Educação pela Universidade de São Paulo. Tem experiência na área de Educação, com ênfase em Sociologia da Educação, atuando e pesquisando nas áreas: Criança e Adolescente, Direitos Humanos, Segurança Pública, Políticas Públicas, Educação e Meio Ambiente. Coordena os Cursos de Pós-graduação Lato Sensu de Formação em Políticas de Gestão e Segurança Pública, Pedagogia e do Núcleo de Trabalhos Comunitários. Professora titular da PUC-SP, membro do Conselho de Ensino e Pesquisa da PUC-SP, do Centro Santo Dias de Direitos Humanos da Arquidiocese de São Paulo e assessora da Pastoral do Menor do Estado de São Paulo.E-mail: ntc@pucsp.br 


\section{INTRODUÇÃO}

Após a participação no curso "Walter Benjamin: experiência, mediação pelas novas tecnologias e surgimento do novo"2, os pesquisadores foram provocados a correlacionar os estudos com os campos de pesquisa, e, dessa forma, refletimos, com base em algumas obras de Benjamin, sobre as práticas sociopedagógicas desenvolvidas por educadores sociais de 18 Centros de Educação Infantil (CEI), geridos pelo Centro Social Nossa Senhora do Bom Parto (Bompar). Essa organização pública não estatal tem como chave interpretativa de suas práticas a Pedagogia Social, em que os educadores sociais vêm se esforçando para refletir sobre sua práxis sob os domínios sociopedagógico, sociopolítico, sociocultural e sociopastoral.

As infâncias indicam pistas reflexivas sobre a problematização do cotidiano e sobre o ser e fazer do educador social. Com base nisso, tomaremos as experiências e práticas desenvolvidas no Bompar que utilizam a Pedagogia Social como elemento dinamizador das relações com as crianças, as famílias, a comunidade, os educadores e as instituições como um possível surgimento do "novo", do "vir a ser" das relações societárias na perspectiva benjaminiana.

As contribuições do pensamento de Benjamin para a educação infantil consistem na elaboração de uma análise da criança e do seu universo lúdico, pois o autor buscava, nas crianças e em suas interações com o outro e com o mundo, fonte para ler a realidade, já que as infâncias interpretam e criam narrativas sobre o cotidiano, que, por vez, passa despercebido pelos adultos.

Walter Benedix Schönflies Benjamin nasceu em 1892, em Berlim, na Alemanha. Em 1935, por ser de família judia, foi para Paris por causa da ascensão do nazismo. Com a ocupação da França pelos alemães em 1940, Benjamin foi para o sul do país com a intenção de ir para os Estados Unidos, contudo foi detido. Como imaginou que seria entregue à Gestapo, Benjamin, em estado de desespero, acabou se suicidando.

Durante sua trajetória intelectual, contribuiu para a fundação da Escola de Frankfurt e dialogou com o materialismo dialético. Seus escritos foram publicados postumamente, alcançando repercussão na segunda metade do século XX. Entre os muitos conceitos explorado por Benjamin, trataremos aqui da "infância", do "narrador", do "novo" e da "experiência".

\section{PROCEDIMENTOS METODOLÓGICOS}

A presente pesquisa se valeu de uma revisão bibliográfica, da análise de documentos institucionais e legislações, da observação com caderno de campo e da roda de conversa com cinco educadoras sociais que atuam em um dos CEI do Bompar.

2 - Promovido pelo Grupo de Pesquisa em Pedagogia Social do Programa de Educação, Arte e História da Cultura da UPM, no período de março a abril de 2018, ministrado pelo professor convidado Dr. Bernd Fichtner, da Universität Siegen. 
A opção pela roda de conversa foi uma estratégia para captar as percepções das educadoras, de modo a favorecer a construção de uma prática dialógica. Como se trata de um instrumento que valoriza as narrativas, ele possibilita a aproximação, o diálogo e a troca entre os participantes.

\begin{abstract}
A Roda de Conversa é um método de ressonância coletiva que consiste na criação de espaços de diálogo, em que os trabalhadores podem se expressar e, sobretudo, escutar os outros e a si mesmos. 0 objetivo é estimular a construção da autonomia dos sujeitos por meio da problematização, da troca de informações e da reflexão para a ação. Trocas de experiências, conversas, discussão e divulgação dos conhecimentos (COELHO, 2007, p. 2).
\end{abstract}

A roda de conversa com as educadoras do Bompar ocorreu a partir do convite às 18 unidades de educação infantil, das quais cinco aceitaram participar da pesquisa. Iniciamos os trabalhos às 10h com acolhida, apresentação do objetivo da pesquisa, explicação da metodologia da roda de conversa e referendo dos acordos, de modo a garantir fluidez no processo, além do compromisso com o sigilo da identidade das participantes, que tiveram seus nomes decodificados em educadora Maria, educadora Marta, educadora Madalena, educadora Rute e educadora Sara. 0 registro da roda de conversa aconteceu por meio de gravações de áudio, transcrição e anotações cursivas.

A característica da dinâmica da roda de conversa é a livre discussão por meio de temas. Nessa oportunidade, a proposta consistiu em falar sobre as experiências sociopedagógicas desenvolvidas na educação infantil.

\title{
INFÂNCIA: CONSTANTES CONSTRUÇÕES E DESCONSTRUÇÕES
}

"No descomeço era o verbo.

Só depois é que veio o delírio do verbo.

0 delírio do verbo estava no começo, lá,

Onde a criança diz: eu escuto a cor dos passarinhos.

A criança não sabe que o verbo escutar não

Funciona para cor, mas para som.

Então se a criança muda a função de um verbo, ele delira.

E pois.

Em poesia que é voz de poeta, que é a voz

De fazer nascimentos -

0 verbo tem que pegar delírio" (BARROS, 1993, p. 3). 
Com o poema de Manoel de Barros iniciamos nossa reflexão sobre a infância. 0 poeta percebe que o bebê e a criança no seu imaginar subvertem a "lógica" adulta. A Pedagogia Social valoriza práticas libertárias que incentivam o lúdico, o brincar heurístico, como forma de ajudar nas descobertas, na autonomia, na apropriação e nas experiências.

Mas nem sempre foi assim, e em muitas sociedades ainda não é, logo, para compreendermos melhor a concepção de infância ao longo da história, utilizaremos a reflexão de Ariès (1981), importante estudo sobre a sociologia da infância. Quando falamos em infância, não nos referimos somente à etapa da vida como uma abstração, mas sim como um conjunto de fatores biopsicossociais, históricos e políticos.

Segundo Ariès (1981), desde o século XII até início do XX, a sociedade vem criando conceitos e modelos para a infância. Logo, o que se assimila em todos os períodos da história é que nem todas as crianças vivem a infância propriamente dita, que sempre variou de acordo com as condições econômicas, sociais e culturais da família, do grupo ou da classe social.

Até o término da Segunda Guerra Mundial, não havia um marco legal de proteção das crianças que, em muitas sociedades patriarcais, eram consideradas inferiores. Durante a ldade Média, a criança era educada por meio de tarefas realizadas com os adultos, e, nesse periodo, temos um alto índice de mortalidade infantil. De acordo com Ariès (1981), como não havia uma percepção de transição da infância para a fase adulta, as crianças eram vistas como pequenos adultos. A sociedade medieval pobre ignorava o termo infância. Para os nobres dessa sociedade, o termo infância designava a primeira idade, em que a dependência relacionava-se à incapacidade física.

A concepção de infância começa a se configurar como tal ao longo de um lento conjunto de alterações de paradigma societário, como costumes, organização social, tecnologias de acesso a bens e poder aquisitivo.

Quando falamos de infância muitas vezes nos deparamos com concepções que desconsideram que os significados que damos a ela dependem do contexto no qual surge e se desenvolve e também das relações sociais nos seus aspectos econômico, histórico, cultural e político, entre outros, que colaboram para a constituição de tais significados e concepções, que, por sua vez, nos remetem a uma imagem de criança como essência, universal, descontextualizada ou então, nos mostram diferentes infâncias coexistindo em um mesmo tempo e lugar. Portanto, ao se buscar uma resposta para a questão sobre a infância e a criança, é necessário uma contextualização sobre a época em que a resposta vai se embasar, e quais referências vão ser usadas para descrever tal conceito, incluindo a classe social e a raça. Porque ser criança na sociedade contemporânea é muito diferente de ser criança nos períodos históricos anteriores (CASTRO, 2013, p. 3). 
Até o advento da Declaração Universal dos Direitos Humanos (1948) e da Declaração Universal dos Direitos das Crianças (1959), as crianças das famílias pobres foram exploradas de diversas formas. As crianças, em períodos distintos, eram utilizadas como mão de obra barata e no século XIX, com a Revolução Industrial, passaram a trabalhar nas fábricas.

A preocupação do Estado com a criança sempre se restringiu a conter a "violência, delinquência e vadiagem", com a institucionalização moral e castigos físicos. Benjamin (1984, p. 90) se opõe a essa lógica e afirma: "a criança proletária nasce dentro de sua classe. [...] Desde o início, ela é um elemento dessa prole, e aquilo que ela deve tornar-se não é determinado por nenhuma meta educacional doutrinária, mas sim pela situação de classe".

Depois da Segunda Guerra Mundial, a infância passa a ser considerada um problema social, econômico e político, e os esforços de grupos organizados tensionam os governos, que começam a definir políticas públicas e sociais de proteção à infância. Inicia-se o pensar a infância como sujeito, com vontades próprias e a capacidade de criar.

\begin{abstract}
A infância é historicamente construída, a partir de um processo de longa duração que the atribuiu um estatuto social e que elaborou as bases ideológicas, normativas e referenciais do seu lugar na sociedade. [...] Fazem parte do processo as variações demográficas, as relações econômicas e os seus impactos diferenciados nos diferentes grupos etários e as politicas públicas, tanto quanto os dispositivos simbólicos, as práticas sociais e os estilos de vida de crianças e de adultos (SARMENTO, 2005, p. 365-366).
\end{abstract}

No Brasil, as políticas de proteção da infância entram em vigor a partir da Constituição Federal (CF) de 1988 por meio de muitas lutas e articulação da Pastoral do Menor, da Pastoral da Criança, do Movimento Meninos e Meninas de rua e de movimentos sociais. A CF de 1988 é a primeira Constituição brasileira que compreende a criança e o adolescente como sujeitos de direito, fixando uma proposta societária de proteção integral à infância e juventude:

\footnotetext{
Art. 227 - É dever da família, da sociedade e do Estado assegurar à criança, ao adolescente e ao jovem, com absoluta prioridade, o direito à vida, à saúde, à alimentação, à educação, ao lazer, à profissionalização, à cultura, à dignidade, ao respeito, à liberdade e à convivência familiar e comunitária, além de colocá-los a salvo de toda forma de negligência, discriminação, exploração, violência, crueldade e opressão (BRASIL, 1988).
}

Dessa forma, a infância passa a ter vez e lugar na sociedade e nas políticas públicas. As crianças se tornam cidadãos de pleno direito - pelo menos no campo jurídico -, cabendo à família, à sociedade e ao Estado o papel de assegurar o pleno desenvolvimento delas.

Com o intuito de concretizar os direitos à infância, os movimentos sociais pressionaram o Estado e contribuiram para a criação do Estatuto da Criança e do Adolescente (ECA), promulga- 
do por meio da Lei n. 8.069, de 1990. No artigo $1^{\circ}$ do ECA, consta o seguinte: "Esta Lei dispõe sobre a proteção integral à criança e ao adolescente". Nos artigos $3^{\circ}$ e $4^{\circ}$, a proteção integral refere-se ao desenvolvimento e à formação dos aspectos cognitivos, afetivos, físicos, sociais, morais, espirituais e culturais em condições de liberdade e dignidade. De acordo com o artigo $4^{\circ}$, toda a sociedade deve "assegurar, com absoluta prioridade, a efetivação dos direitos referentes à vida, à saúde, à alimentação, à educação, ao esporte, ao lazer, à profissionalização, à cultura, à dignidade, ao respeito, à liberdade e à convivência familiar e comunitária" (BRASIL, 1990).

A concepção de infância como sujeito está constituida de forma ampla na legislação brasileira: CF, ECA, Lei de Diretrizes e Bases da Educação Nacional, Referencial Curricular Nacional para a Educação Infantil, Diretrizes Curriculares Nacionais para a Educação Infantil, entre outros.
Sujeito histórico e de direitos que, nas interações, relações e práticas cotidianas que viven- cia, constrói sua identidade pessoal e coletiva, brinca, imagina, fantasia, deseja, aprende, observa, experimenta, narra, questiona e constrói sentidos sobre a natureza e a sociedade, produzindo cultura (BRASIL, 2010, p. 12).

Porém, mesmo com o avanço do marco legal, a realidade da infância ainda é desigual entre as diversas classes sociais. As crianças ainda são vítimas de abuso e exploração sexual, trabalho infantil, violência doméstica e de tráfico de seres humanos. São aliciadas pelo crime organizado e vivem em situações de risco, e o Estado, seja por morosidade, mau gerenciamento ou política de manutenção, reforça a cultura clientelista, autoritária e repressiva e não viabiliza os sonhos de prioridade absoluta.

Como então a infância pode se desenvolver plenamente como sujeitos de direitos? 0 que é ser criança, no Brasil, no estado de São Paulo, na cidade de São Paulo, na zona leste dessa cidade?

Segundo o Fórum Brasileiro de Segurança Pública ${ }^{3}, 21$ dos 27 estados têm escala de alta e média vulnerabilidade, desigualdade e risco social. São Paulo, por exemplo, representa uma contradição: é, ao mesmo tempo, a cidade mais rica e, também, a mais desigual. São Paulo, que está entre as dez maiores cidades do mundo, tem um claro contraste social: bairros de familias ricas com infraestrutura convivem com bairros de familias pobres e sem infraestrutura, como saneamento ou equipamentos públicos suficientes.

0 Relatório Anual da Oxfam Brasil 2017 - A distância que nos une - aponta que, dos 97 distritos da cidade de São Paulo, o acesso às políticas públicas é pior nas periferias da cidade, como destaca a Figura 1. 
Figura 1 Políticas públicas

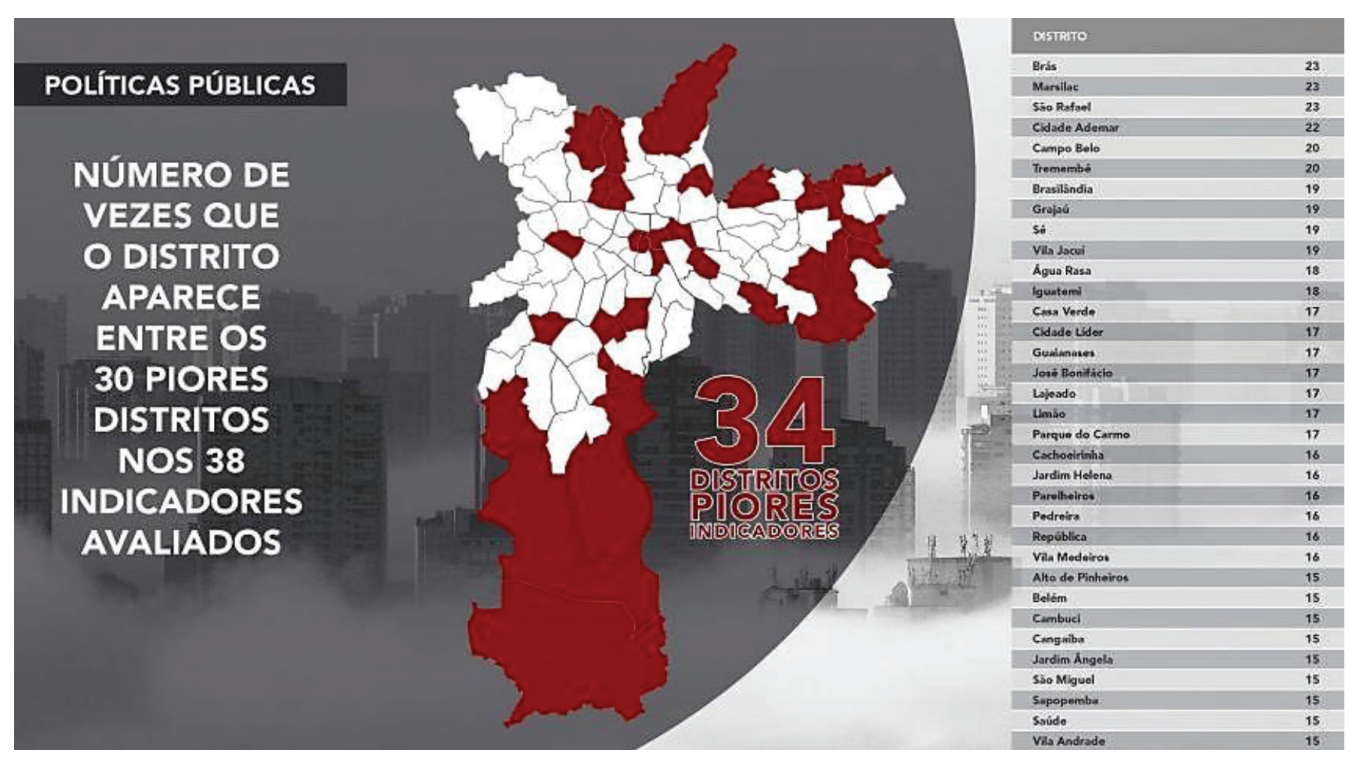

Fonte: Rede Nossa São Paulo. Disponivel em:

https://www.nossasaopaulo.org.br/portal/arquivos/mapa-da-desigualdade-2017.pdf. Acesso em: 21 maio 2018.

Não é por coincidência que os distritos com piores indicadores de avaliação estão localizados nos extremos da cidade, onde o crescimento populacional e habitacional se deu de maneira desorganizada, sem planejamento estratégico, aonde as políticas públicas chegaram bem depois da ocupação territorial e por meio de muitas reivindicações. No entanto, essas políticas continuam insuficientes.

São Mateus e Sapopemba - território de atuação do Bompar - estão entre os distritos com os piores Índice de Desenvolvimento Humano (IDH) da cidade de São Paulo. Por exemplo, o IDH de Sapopemba é 0,785. Esses territórios representam setores com baixíssimo conforto socioeconômico e ambiental e com pouquíssimas ofertas de serviços públicos básicos.

Faltam equipamento de esporte, lazer e cultura. As famílias que residem nesses distritos estão enquadradas nos grupos 5 e 6, o que corresponde à classificação de alta e muito alta vulnerabilidade, conforme o Índice Paulista de Vulnerabilidade Social ${ }^{6}$.

5 - Disponivel em: https://www.archdaily.com.br/br/786534/os-20-distritos-com-os-idh-mais-altos-e-mais-baixos-de-sao-paulo. Acesso em: 21 maio 2018.

6 - Fonte: IBGE, Censo, 2010; Fundação Seade, IPVS 2010, 2013; SMDU, MDC, 2009. Elaboração: Smads/Cops/Centro de Geoprocessamento, maio de 2013. Disponivel em: https://www.prefeitura.sp.gov.br/cidade/secretarias/upload/chamadas/03_1400688004. pdf. Acesso em: 2 fev. 2020. 
Então, ao falarmos de infância, devemos considerar que, mesmo com marco legal estabelecido, as variáveis econômicas, o acesso ou não a equipamentos públicos, os diferentes territórios e as vulnerabilidades são cruciais para compreender o conceito das infâncias, no plural, que indicam as múltiplas variações em cada sociedade, em cada cidade. Por exemplo, existe uma pluralidade cultural na qual as crianças se inserem, como define Sarmento (2004), pois se compreendem infâncias como "culturas da infância", tendo em vista que elas se manifestarão de modos diferentes de acordo com a classe social, o território e a oportunidade de acesso às políticas públicas de auxílio no seu desenvolvimento.

Logo, entendemos as infâncias como "uma categoria social do tipo geracional pela qual se revelam as possibilidades e os constrangimentos da estrutura social" (SARMENTO, 2005, p. 363). O Referencial Curricular Nacional para a Educação Infantil corrobora nossa reflexão ao conceber que

\begin{abstract}
[...] em uma mesma cidade existam diferentes maneiras de se considerar as crianças pequenas dependendo da classe social a qual pertencem, do grupo étnico do qual fazem parte. Boa parte das crianças pequenas brasileiras enfrentam um cotidiano bastante adverso que as conduz desde muito cedo a precárias condições de vida e ao trabalho infantil, ao abuso e exploração por parte de adultos. [...] Essa dualidade revela a contradição e conflito de uma sociedade que não resolveu ainda as grandes desigualdades sociais presentes no cotidiano. A criança como todo ser humano, é um sujeito social e histórico [...] É profundamente marcada pelo meio social em que se desenvolve, mas também o marca. [...] As crianças possuem uma natureza singular, que as caracteriza como seres que sentem e pensam o mundo de um jeito muito próprio. [...] Compreender, conhecer e reconhecer o jeito particular das crianças serem e estarem no mundo é o grande desafio da educação infantil e de seus profissionais (BRASIL, 1998, p. 21-22).
\end{abstract}

Por isso, outro aspecto a ser considerado é a construção social do adultocentrismo no processo de ensino-aprendizagem, modelo autoritário em que a criança é exposta ao mundo adulto precoce, abruptamente e/ou de forma negligente. Em outras palavras, trata-se da influência adulta no desenvolvimento das crianças, não como facilitadora, mediadora, mas sob valores capitalistas, expostas ao mundo de competição, consumo, erotização, violência, corrupção.

0 mundo adulto, em sobreposição ao mundo infantil, desconsidera os aspectos singulares da própria infância; o adultocentrismo considera a infância - no singular - apenas como período de transição.

0 sistema capitalista utiliza-se dessa lógica adultocêntrica para silenciar a criatividade das crianças, impondo padrões de consumo e ditando o que é brincadeira, o que é brinquedo, o que são "coisas" de menino e de menina, sempre a partir do paradigma adulto: meninos 
brincando de carrinho e usando roupa na cor azul, e meninas brincando de boneca e usando roupas rosa.

Para Benjamin (1984, p. 77), as crianças, mesmo educadas sob esse prisma, subvertem e recriam novas dinâmicas relacionais:
[...] menos empenhadas em imitar as obras dos adultos estabelecem entre os mais diferen- tes materiais, através daquilo que criam em suas brincadeiras, uma nova e incoerente rela- ção. Com isso as crianças formam seu próprio mundo de coisas, mundo pequeno inserido num maior.

Assim, o cotidiano adulto afeta as crianças, porém elas, por meio de seus grupos, criam formas de ser e estar no mundo.

\begin{abstract}
Quando o educador se coloca como autor e protagonista da relação, não dá subsídios para que essa criança possa desenvolver o real brincar. Quando ele fecha a proposta não observando a criança ou em falas como "Hoje nós vamos ao parque, mas não é para brincar com a terra", eu podo uma situação que poderia ser sensacional e não deixo a criança fazer o papel de criança (Depoimento da educadora Marta).
\end{abstract}

Acreditamos que uma formação intencional pode ajudar o educador social a inserir na educação infantil a desconstrução dos valores adultocêntricos, o que significa garantir a possibilidade de as infâncias existirem como crianças singulares, plurais, sujeitos de direitos que são capazes de manifestar seus desejos não fetichizados pelo mercado, mas exploratórios do mundo.

Benjamin, nas obras Experiência, jogos e brinquedos, Rua de mão única, Infância berlinense, entre outras, aponta que experiência do adulto sobre a criança gera uma problemática geracional, pois os adultos subestimam a capacidade de a infância intercambiar as próprias experiências: "a essência do brincar não é um 'fazer como se', mas um 'fazer sempre de novo.' Transformação da experiência mais comovente, em hábito" (BENJAMIN, 1984, p. 75).

0 brincar espontâneo para a criança é a forma de ler o mundo e formular respostas para os dramas sociais a partir de suas experiências: "Onde existe experiência [Erfährung] no sentido estrito da palavra, certos elementos do passado individual combinam-se na memória com matéria proveniente do passado coletivo" (BENJAMIN, 1985, p. 316).

Então concebemos a criança como ser pensante, que sonha e cria, que formula respostas societárias e subverte a lógica opressora: "Compreendendo-as como sujeitos autônomos, produtoras e produtores de culturas infantis" (SANTOS et al., 2013, p. 146). 


\section{A PEDAGOGIA SOCIAL COMO TERRA FECUNDA PARA PRÁTICAS NA INFÂNCIA}

A Pedagogia Social nada mais é do que uma ciência da educação que tem por objetivo uma nova relação social e, "de certa forma, uma contrapedagogia que busca instaurar uma nova cultura, a cultura da solidariedade que possa neutralizar a banalização da vida à qual as elites brasileiras se acostumaram" (GRACIANI, 2001, p. 13).

A Pedagogia Social surge como um novo paradigma pedagógico, reunindo, nas práticas sociopolíticas, socioculturais, sociopedagógicas e sociopastorais, propostas capazes de contribuir para a formação do indivíduo, para que ele seja capaz de interagir com a sua realidade e transformá-la.

Logo, essas práticas consistem em uma contribuição fundamental para que o educando construa uma representação de si mesmo e do mundo do qual faz parte. Nesse processo, ele desvela criticamente o sentido e o significado de sua presença diante do mundo, dos outros homens e de si mesmo, a partir dos elementos que o ligam à totalidade mais ampla do social: "Atualmente a Pedagogia Social parece orientar-se sempre mais para a realização prática da educabilidade humana voltada para pessoas que se encontram em condições sociais desfavoráveis" (CALIMAN, 2006, p. 19).

Segundo Pereira (2011, p. 49), a Pedagogia Social visa à "reconstrução de uma cidadania possível, mesmo no sistema capitalista, embora fosse necessário defender uma cidadania fora desse sistema". Já para Souza Neto (2010, p. 53), refletir sobre a construção das práticas sociais pela perspectiva da Pedagogia Social "implica a discussão do sentido e da práxis da cultura de direitos".

Para Graciani (2001), a Pedagogia Social caracteriza-se como movimento dialético que não se restringe a técnicas, métodos ou estratégias de trabalho, mas se funda num processo de construção de conhecimentos que se apropria criticamente da realidade para transformá-la. Graciani (2014) complementa que a metodologia é centrada na pessoa e baseada na proposta de desenvolvimento, possibilitando soluções e práticas mais abrangentes. Para tal, faz-se necessária a utilização de abordagens interdisciplinares.

[...] não se limita ao desenvolvimento cognitivo e de habilidades individuais. Ela dá primazia ao sujeito mergulhado nos dramas sociais, chamado a responder às exigências da vida e a encontrar um sentimento existencial, leva em conta o desenvolvimento físico, moral, estético e intelectual do sujeito e de grupos em conflito social, marginalizados, com dificuldades econômicas e que necessitam desenvolver processos de convivência e aprendizagem. Ela é uma estratégia possivel para diminuir os processos de reprodução da desigualdade e das mazelas sociais. Parece óbvio que a ação dos sujeitos envolvidos e o sentido da vida não são dados, mas construidos, e materializam-se num contexto social determinado (SOUZA NETO, 2010, p. 70). 
Dessa forma, a Pedagogia Social procura ser uma contribuição para o rompimento do ciclo de exclusão e marginalização e, associada à educação infantil, torna-se um potencializador no processo de desenvolvimento integral, já que sua proposta metodológica se inscreve como criadora das condições lúdicas para que o fazer educativo ocorra em um espaço de ação - reflexão, ação dos principais desafios e das dificuldades concatenados com a pluralidade dos acontecimentos cotidianos.

As práticas de valorização da cultura, da corporeidade, do imaginar, do brincar, do desenhar e do cuidar possibilitam que a criança contextualize a sua realidade, problematizando-a. Ela pode se distanciar do seu mundo e imergir no "faz de conta", de modo a aprender e apreender por meio da comunicação, do diálogo e principalmente dos atos concretos e da relação com o educador social.

Entendemos que experiências sociopedagógicas desenvolvidas na educação infantil devem ser divulgadas, de modo a subsidiar outros educadores para fomentar novas práxis que respondam à realidade das infâncias em diferentes territórios e condições de vulnerabilidades. Como é o caso dos CEI do Bompar.

\section{ALGUMAS EXPERIÊNCIAS SOCIOPEDAGÓGICAS DESENVOLVIDAS NOS CEI DO BOMPAR}

O Bompar há décadas vem contribuindo para a formulação de políticas na educação infantil e assistência social na cidade de São Paulo. Cabe destacar que essa organização social tem raízes na teologia, filosofia e pedagogia da libertação e, em seus diferentes períodos de existência, transitou por diferentes concepções libertárias de matriz comunitária, popular e social, e bebeu delas.

\footnotetext{
[...] ligado à Pastoral do Menor, foi fundado em 1946, quando um grupo de senhoras católicas que frequentavam a Paróquia Nossa Senhora do Bom Parto, no Tatuapé - bairro da Zona Leste I de São Paulo, decidiram se unir e começar a desenvolver ações de formação e capacitação profissional a mulheres menos favorecidas, visando a geração de renda (CENTRO SOCIAL NOSSA SENHORA DO BOM PARTO, 2020, p. 1).
}

Sob forte animação, Dom Paulo Evaristo Arns, Dom Luciano Pedro Mendes de Almeida, nas décadas de 1970 e 1980, e a irmã Judith Elisa Lupo, na década de 1990 em diante, reuniram pessoas comprometidas com a defesa da vida e apoiaram e organizaram a atuação das Comunidades Eclesiais de Base (CEB) no atendimento aos direitos de crianças, adolescentes, jovens e famílias, na proteção desses direitos e na luta por eles. 
Hoje, em suas 53 unidades e uma sede administrativa, o Centro Social Nossa Senhora do Bom Parto atende diariamente mais de 15.000 crianças, adolescentes, jovens e respectivas famílias, adultos em situação de rua e idosos. Tem como MISSÃO "Articular e contribuir para a Defesa dos Direitos das crianças e dos adolescentes, familiares e população em situação de rua da Região Episcopal Belém de São Paulo, através de programas socioeducativos, desenvolvidos em unidades de atendimento, favorecendo o protagonismo social [...]" (CENTRO SOCIAL NOSSA SENHORA DO BOM PARTO, 2020, p. 1).

Atualmente os trabalhos estão sendo desenvolvidos em bairros das subprefeituras de São Mateus, Vila Prudente, Sapopemba, Aricanduva e Mooca, por meio das políticas de educação - CEI -, de assistência e desenvolvimento social - os Centros para Crianças e Adolescentes, Centros de Desenvolvimento Social e Produtivo, Serviços de Acolhimento Institucional para Crianças e Adolescentes, Núcleo de Convivência para Idosos, Centro de Convivência para População em Situação de Rua, albergue para pessoas em situação de rua - e da Saúde - , de consultório na rua e Programa de Acompanhante de Idosos, além do Programa de Aprendizagem Profissional na inserção de jovens ao primeiro emprego.

Sobre os CEI do Bompar, diariamente são atendidas cerca de 3.166 crianças de 0 a 4 anos, em 18 unidades. A Tabela 1 apresenta o quadro de recursos humanos.

Tabela 1 Função e quantidade de funcionários das creches/dos CEI

\begin{tabular}{|c|c|c|c|c|c|}
\hline \multicolumn{6}{|c|}{ Função e quantidade } \\
\hline Diretora & $\begin{array}{c}\text { Coordenadora } \\
\text { pedagógica }\end{array}$ & $\begin{array}{c}\text { Professora de } \\
\text { desenvolvimento } \\
\text { infantil }\end{array}$ & $\begin{array}{c}\text { Auxiliar de berçário, } \\
\text { auxiliar de cozinha, } \\
\text { auxiliar de limpeza e } \\
\text { vigia }\end{array}$ & $\begin{array}{c}\text { Auxiliar } \\
\text { administrativo }\end{array}$ & Cozinheira \\
\hline 18 & 18 & 303 & 102 & 6 & 18 \\
\hline
\end{tabular}

Fonte: Recursos humanos do Centro Social Nossa Senhora do Bom Parto (base: out. 2019).

Nas últimas décadas, a educação infantil vem constituindo importantes paradigmas e concepções de como fazer pedagogia, de como conceber os sujeitos educador, bebês e crianças em seus desenvolvimentos, direitos e desafios.

0 processo sociopedagógico do Bompar foi sistematizado em dois documentos fundantes: Projeto Político-Pedagógico Institucional (PPP-I) e Projeto Político-Pedagógico para Educação Infantil (PPP-EI).

Trata-se de projeto porque tem a ver com o caminho escolhido e calcado em sonhos, desejos do novo. É político porque toda ação humana afeta o indivíduo, o outro e as estruturas, é uma construção cultural, histórica, é um modo de constituir relações societárias, 
logo não é neutra. E é pedagógico quando se constitui uma ciência do aprender e ensinar, do ensinar aprendendo.

0 Projeto Político-Pedagógico (PPP) exprime os ideais e os fazeres para a construção de uma nova civilização, pautada em uma nova forma de relação entre os diversos atores sociais. Como seu caráter pedagógico é delineado pelo grau de disposição interior do que se quer ensinar para os grupos aprenderem, é intencional.

De acordo com Graciani (2014), o PPP se refere a uma proposta educativa que abarca e abrange todos os campos existenciais da realidade. 0 perfil do projeto é por natureza de denúncia e proposta ante os conflitos sociais e entre o acirramento de forças e o de grupos de interesses de conservadores ou progressistas - quer por mudanças ou transformações. A prática social inserida na construção do conhecimento não é neutra, e assim o PPP é o documento ordenador das ações e dos modelos de gestão a serem executados, exige reflexão, finalidade nas ações educativas, integração à comunidade, desencadeia os processos e tem um compromisso com todos os envolvidos na ação educativa.

0 PPP constitui e reflete a realidade da comunidade em todas as possibilidades, como instrumento e mecanismo clarificador da ação educativa, considera os vários saberes, exige a incorporação da matriz de cultura, exige um processo investigativo permanente, requer atenção ao cognitivo, ao afetivo e à corporeidade, é composto de planejamento participativo, trabalho coletivo e avaliação emancipatória. 0 PPP precisa de um referencial teórico e prático que subsidie a sua construção.

O PPP-I foi uma construção coletiva, democrática, com envolvimento de toda a comunidade educativa, representado por diferentes enfoques e abordagens de vários autores, como: Jean Piaget, Lev Semionovitch Vygotsky, Emmi Pikler, Paulo Freire e Bernardo Toro, Jacques Delors, Antônio Carlos Gomes da Costa, Maria Stela Santos Graciani, Edgar Morin, João Clemente de Souza Neto e Henry Wallon. Dessa forma, pode-se afirmar que a metodologia do Bompar é alinhada com a concepção de Pedagogia Social, pois esta é centrada na pessoa, nas relações, no desenvolvimento, na apropriação, nas descobertas, nos direitos e na cidadania.

0 PPP-El representa a concepção e os princípios da educação infantil em consonância com a legislação vigente e serve de instrumento para a elaboração da prática pedagógica diária, de acordo com a etapa de desenvolvimento das crianças, além de orientar a organização e o funcionamento dos CEl, definindo metas, indicadores, plano de ação, projetos, calendário, entre outros. A elaboração do PPP-El ocorre de acordo com a necessidade do processo sociopedagógico realizado em cada unidade educacional. É uma metodologia de trabalho que possibilita dar significado à ação de todos os sujeitos dos CEl e ressignificá-la.

As Unidades de Educação Infantil/Creches do BOMPAR têm por objetivo a proteção e promoção à infância, assegurando um processo socioeducativo que visa proporcionar o desenvolvimento integral e harmonioso da criança, a partir do acesso a processos de apropriação, 
renovação e articulação de conhecimentos e aprendizagens de diferentes linguagens, assim como do direito à saúde, à liberdade, à confiança, ao respeito, à dignidade, à brincadeira, à convivência e à interação com outras crianças (CENTRO SOCIAL NOSSA SENHORA DO BOM PARTO, 2018, p. 12)

A proposta sociopedagógica do Bompar deriva do posicionamento ideológico, filosófico, espiritual e técnico. Nesse sentido, os princípios básicos e gerais que a norteiam são pautados pela ética, pelos direitos e pela estética. Ou seja, a ação pedagógica pauta-se pelo exercício da criticidade, sensibilidade, criatividade, ludicidade e liberdade de expressão nas diferentes manifestações artísticas e culturais.

A abordagem sociopedagógica compreende a criança como produtora de conhecimento e cultura, que deve ser vista como pessoa em processo de desenvolvimento, ou seja, como sujeito histórico, social e de direitos, com poder de criação e imaginação, além de possuir recursos próprios para interagir com o outro e com o meio, construindo a sua identidade pessoal e coletiva, autonomia, sentidos sobre a natureza e a sociedade, produzindo cultura, favorecendo o vínculo familiar e comunitário.

Dentro da Pedagogia Social, o sociopedagógico é um domínio que tem como área de desenvolvimento e formação "a Infância, Adolescência, Juventude e Terceira Idade" (SILVA; SOUZA NETO; MOURA, 2009, p. 285) a partir de "processos sociais que requerem o exercício de direitos individuais, sociais e políticos como expressão dos Direitos Humanos da cidadania" (SILVA; SOUZA NETO; GRACIANI, 2017, p. 15). Acreditamos que a mediação

\footnotetext{
[...] sociopedagógica neste domínio tem como objetivo principal o desenvolvimento de habilidades e competências sociais que permitam às pessoas a ruptura e superação das condições de marginalidade, violência e pobreza que caracterizam sua exclusão social. Por suas características, são locus privilegiados para a intervenção sociopedagógica os abrigos, as unidades de internação de adolescentes autores de ato infracional, asilos para idosos, instituições psiquiátricas e unidades prisionais, mas também são consideradas a rua, a família e a empresa (SILVA; SOUZA NETO; MOURA, 2009, p. 285).
}

Segundo o PPP-El, a concepção de educação e aprendizagem complementa a família e a comunidade como forma de assegurar um desenvolvimento integral, propondo uma dialética relação de educar e cuidar.

Cuidar da criança é uma ação complexa que envolve diferentes fazeres, gestos, precauções, atenção, olhares. Refere-se a planejar situações que ofereçam à criança acolhimento, estímulo, desafio, de modo que ela satisfaça suas necessidades de diversos tipos e aprenda a fazê-lo de forma cada vez mais autônoma. Quando a criança percebe que está sendo cui- 
dada, sente-se segura. Aos poucos ela vai adquirindo autonomia para tentar fazer sozinha aquilo que fazia com auxílio de alguém, até o momento em que se torna independente, cuidando de si mesma, com a proteção da família e dos profissionais da educação infantil. Já educar a criança é criar condições para ela apropriar-se de formas de agir e de significações presentes em seu meio social, formas estas que a levam a constituir-se como um sujeito histórico. Ao fazê-lo, a criança desenvolve sua afetividade, motricidade, imaginação, raciocinio e linguagem, formando um autoconceito positivo em relação a si mesma. 0 educador cuida e educa quando promove e acolhe as interações que a criança estabelece com outras crianças e quando organiza e dá oportunidade para que elas compartilhem experiências e saberes (CENTRO SOCIAL NOSSA SENHORA DO BOM PARTO, 2018, p. 16).

Propiciar situações de cuidado, brincadeiras e aprendizagens orientadas de forma integrada contribui para o desenvolvimento das capacidades infantis de relação interpessoal, de ser e de estar com os outros. A partir do brincar com o outro, a criança expressa de forma lúdica as experiências por meio de objetos imagéticos e não estruturados.
[...] nada é mais adequado à criança do que irmanar em suas construções os materiais mais heterogêneos - pedras, plastilina, madeira, papel. [...] um simples pedacinho de madeira, uma pinha ou uma pedrinha reúnem na solidez, no monolitismo de sua matéria, uma exu- berância das mais diferentes figuras (BENJAMIN, 1984, p. 91-92).

Sendo o brincar então reconhecido como fundante para o desenvolvimento dos bebês e das crianças, como esse processo ocorre na prática? Para a educadora Sara, existe um método de desconstrução do modo de pensar o brincar:

\begin{abstract}
A gente trabalha com os elementos da natureza de diversas formas. Eu montei um território, achando que eles iam fazer bolos, dei até assadeiras, mas eles colocaram a terra dentro da água e fizeram um suco de maracujá e um bolo de folhas. Então a gente imagina uma coisa, mas, como não somos um ser brincante, eles vão muito além da nossa intenção.
\end{abstract}

Assim "a criança não faz distinção entre o brinquedo e o que ele significa, mas a utilidade que terá nas representações que serão feitas com ele" (BISCOLI, 2005, p. 29), o que reforça a conclusão da educadora Sara. Logo, é no brincar que envolve o lúdico, o imaginar que os bebês e as crianças se tornam protagonistas.

A criança é o protagonista quando brinca; o educador é protagonista quando ele prepara o ambiente para observar. 0 ambiente sendo propositor, ele vai potencializar as crianças. A educadora só vai intervir quando ela for chamada: "'Pro', vem comer um doce que eu fiz". 
Ai ela foi convidada a entrar na brincadeira; em nenhum momento ela vai entrar na brincadeira se não for convidada (Depoimento educadora Maria).

0 brincar é o meio, a linguagem da qual as crianças se utilizam para comunicar suas experiências culturais no mundo adulto e, da mesma forma, vão aprendendo sobre si mesmas, sobre os outros, sobre o mundo que as cerca.

Outro aspecto importante do processo sociopedagógico é a perspectiva da formação integral que visa ao ser na sua integralidade, em suas dimensões constitutivas - expressivo-motora, afetiva, cognitiva, linguística, ética, estética e sociocultural. A integração com a família é primordial para o processo educativo, sobretudo quando se consideram a maneira como é formada e a singularidade e configuração dela. Benjamin (1984, p. 77) defende que as crianças formam seu próprio mundo de coisas, mundo pequeno inserido em um mundo maior:

Se a criança não é nenhum Robinson Crusoe, assim também as crianças não se constituem nenhuma comunidade isolada, mas sim uma parte do povo e da classe de que provém. Da mesma forma seus brinquedos não dão testemunho de uma vida autônoma e especial; são isso sim, um mudo diálogo simbólico entre ela e o povo [...].

0 acolhimento dá sustento e confiança, constrói vínculos e parcerias, elementos indispensáveis ao desenvolvimento e ao processo de aprendizagem. 0 acolhimento à criança não se restringe a apenas um período, mas deve ocorrer de forma contínua.
E mais, a criança deve ter o direito, principalmente quando inserida em contextos educacio- nais, de viver a plenitude de sua infância, pois a pedagogia proletária demonstra sua supe- rioridade ao garantir às crianças a realização de sua infância [...] (BENJAMIN, 1984, p. 87).

Logo as vivências sociopedagógicas nas unidades de educação infantil devem primar pelos campos de aprendizagem que valorizem a descobertas e as experiências, mas com muito zelo para também não pedagogizar a infância. As crianças vão se constituindo em sua singularidade aprendendo e apreendendo brincando e interagindo em vários espaços pedagógicos, com contato com a natureza, as formas, as cores, os cheiros, os sabores e as trocas intergeracionais.

Para que as crianças possam exercer sua capacidade de criar é imprescindivel que haja riqueza e diversidade nas experiências que Ihes são oferecidas nas instituições, sejam elas mais voltadas às brincadeiras ou às aprendizagens que ocorrem por meio de uma intervenção direta (BRASIL, 1998, p. 27). 
0 ambiente é outro aspecto sociopedagógico revelador de intencionalidades, pois os espaços respeitam a potencialidade infantil. Os ambientes acabam por ser a extensão da criança que vive essas interações, em plenitude, intensamente, a partir do fazer e do experimentar: "É preciso, pois, deixar o ambiente suficientemente pensado para estimular a curiosidade e a imaginação da criança, mas incompleto o bastante para que ela se aproprie e transforme esse espaço através da sua própria ação [...]" (LIMA, 1989, p. 72).

Para o Bompar, outro elemento sociopedagógico é a escuta atenta dos bebês e das crianças, que "ensinam e educam os atentos educadores" (BENJAMIN, 1984, p. 88), tendo em vista o protagonismo dos atendidos pelo CEI, pois a criança tem direito a ser ouvida. Assim, "observar e escutar as autorias dos bebês e crianças é tão importante [...] o educador precisa ter esse olhar atento e sensivel para cada situação, porque, partindo daí, ele vai criar as novas possibilidades" (Depoimento educadora Madalena).

Escutar e ouvir cada criança é fundamental para a construção das atividades, de modo a garantir a presença de vozes, opiniões, anseios e desejos dos bebês e das crianças. "0 mundo da percepção infantil está marcado, por toda parte, pelos vestígios da geração mais velha, com os quais a criança se defronta" (BENJAMIN, 1984, p. 72), portanto escutar a criança é permitir aflorar as percepções. A criança é capaz de ressignificar e elaborar novos paradigmas, o que exige do educador uma abertura para ela. Nesse sentido, o educador social deve ser um eterno aprendente, um eterno pesquisador de suas experiências.

\begin{abstract}
Cada uma de nossas experiências possui efetivamente conteúdo. Nós mesmos conferimos- Ihe conteúdo a partir do nosso espírito. - A pessoa irrefletida acomoda-se no erro. "Nunca encontrarás a verdade", brada ela àquele que busca e pesquisa, "eu já vivenciei isso tudo". Para o pesquisador, contudo, o erro é apenas um novo alento para a busca da verdade (Espinosa). A experiência é carente de sentido e espírito apenas para aquele já desprovido de espírito (BENJAMIN, 2009, p. 23).
\end{abstract}

E a partir da escuta e observação, o educador se coloca como pesquisador, analisando criticamente sua prática em um constante movimento de ação-reflexão-ação, observado na fala da educadora Rute: "Como eles estão brincando? 0 que eles estão trazendo para a gente? Como está sendo esse aprendizado? Como eu preparo espaço para que aconteça essa brincadeira? Qual a minha intervenção?". E complementa:

\footnotetext{
0 professor também é aquele que vai questionar, não é no sentido de aquilo está certo ou errado. Diante da situação, ele não vai dizer "é assim". E, sim, fazer boas perguntas; a partir da investigação ele vai pensar em outras possibilidades. Num próximo momento eu posso ampliar o espaço da brincadeira (Depoimento educadora Rute).
} 
Entendemos, a partir das obras de Benjamin, que o bom educador social se torna o que ele chama de "narrador da história", que, de acordo com o autor, está em extinção. De acordo com Benjamin (1992, p. 27), "É cada vez mais raro encontrar pessoas que saibam narrar qualquer coisa com correção [...]. É como se uma capacidade que nos parecia inalienável, a mais segura de todas, nos tivesse sido tirada: a capacidade de trocar experiências".
[...] a arte de narrar, que prospera por muito tempo no âmbito do trabalho das mãos - nos campos, nos mares e depois nas cidades -, é ela mesma uma espécie de forma artesanal da comunicação. 0 importante para ela não é transmitir o puro "em si" da matéria, como se se tratasse de uma informação ou de um relatório. Faz descer à matéria a vida de quem conta, para a fazer emergir de novo a partir dele [...] (BENJAMIN, 2013, p. 157-158).

Na educação infantil, o educador social "[...] vai buscar a sua matéria, a experiência, a própria ou as que the foram relatadas. E volta a transformar essa matéria em experiência daqueles que o ouvem contar" (BENJAMIN, 2013, p. 152) Assim as propostas sociopedagógicas que visam ao cuidado de si, do outro, do ambiente, aprender a aprender, aprender a conviver, aprender a ser e aprender a fazer, relacionando com o brincar e imaginar, educar e cuidar, explorando linguagem corporal, verbal e artística - musical, teatral, desenho e plástica -, explorando a natureza e a cultura imersa: "Rodeadas por um mundo de gigantes, as crianças criam para si, brincando, o pequeno mundo próprio" (BENJAMIN, 1984, p. 85).

\section{CONSIDERAÇÕES FINAIS}

Para o Bompar, a criança, desde o nascimento, é produtora de conhecimento e cultura, e deve ser vista como sujeito em processo de desenvolvimento, como sujeito de direitos, seu social e histórico com poder de imaginação e criação, além de possuir recursos próprios para interagir com o outro e construir a própria autonomia e resistência.

Ao falarmos de crianças, compreendemos a existência de múltiplas infâncias, não podendo cair no erro de categorizar ou conceber que todo ser humano tem uma infância igual. Há muitas variáveis: condições socioeconômicas, acesso a equipamentos - públicos ou privados -, classes sociais, a cor da pele, o lugar onde se vive - regiões centrais ou periféricas -, exposição às várias formas de violência, descriminalização e preconceito.

0 filósofo alemão Walter Benjamin enfatiza a recuperação de tradições e formas de pensar deixadas de lado pelo registro histórico hegemônico, para fornecer instrumentos possíveis de criticar as estruturas sociais do presente. Portanto, é imprescindivel que cada grupo retome as próprias narrativas, histórias e experiências, de modo a romper com o adultocentrismo e a colonização da infância. É fundamental que se destaquem as potencialidades das 
crianças e tudo aquilo que elas têm a nos ensinar. É preciso reconhecer sobretudo quais paradigmas estão sendo gestados e quais estão em processo de desconstrução.

A proposta da Pedagogia Social adotada pelo Bompar é criadora de condições lúdicas para que o fazer educativo ocorra em um espaço de ação-reflexão-ação, de modo a contextualizar as relações de vida - opressor e oprimido - com o educando, em que ele possa assim aprender e apreender.

Nesse contexto, as crianças são apresentadas a uma diversidade de linguagens audiovisuais e plásticas, corporeidades e aspectos culturais. A arte tem ajudado nos caminhos mais eficazes na interação com o mundo, por meio de dramatização, brincadeiras, desenhos, pinturas, poesia, jogos, entre outros. Nesse processo, as crianças, com base na magia da criatividade, reinventam, de maneira informal, autônoma e independente, a realidade e constroem a própria identidade por meio do processo dialógico.

Portanto, os elementos sociopedagógicos desenvolvidos pelos CEI do Bompar são fundamentais para o empoderamento dos excluídos que, em síntese, constroem uma nova sociabilidade que consiste em cuidar de si, do outro e do ambiente. Brincam e imaginam, exploram as linguagens corporais, verbais e artísticas de forma protagônica, e aprendem a ser, conviver e fazer.

Para isso, o educador social desenvolve uma escuta atenta dos bebês e das crianças, e reconhece e valoriza as diversas infâncias, a comunidade como espaço de potencializar o sujeito e o território, o ambiente como revelador de intencionalidades e a formação que visa ao ser na sua integralidade. 0 educador social, ao desconstruir o adultocentrismo, concebe a criança como produto e produtora de cultura, sujeito histórico de direitos que exercita a criatividade, sensibilidade, ludicidade e liberdade de expressão, primando por uma ética e estética libertárias.

Pensar em uma educação emancipatória que empodera desde o nascimento pressupõe desconstruir várias concepções adultocêntricas e caminhar para compreensão de que a criança é um sujeito histórico que produz cultura. Por isso, devem-se buscar na Pedagogia Social teorias e metodologias para pensar as crianças, as infâncias e o processo de gestação do novo na educação infantil.

Assim, a Pedagogia Social pode e deve ser o meio pelo qual os filhos dos proletariados iniciam processos de emancipação e consciência crítica sobre a realidade, como já destacava Benjamin. As ações sociopedagógicas podem e devem ser essa contribuição para o rompimento do ciclo de exclusão e marginalização, e canais de escuta das vozes ignoradas ao longo da história. Entretanto, precisamos começar ouvindo as crianças, mesmo quando elas ainda não falam, não andam, não leem e não escrevem como os adultos.

Logo, o Bompar, ao atender mais de 3 mil bebês, crianças e suas famílias da zona leste de São Paulo diariamente, com o viés libertador, coloca-se como espaço de resistência na medida em que contribui para a formação do sujeito com autonomia, amorosidade e cuidado, respeitando o processo de desenvolvimento. 
0 Bompar propicia condições para que as crianças e as infâncias possam manifestar suas experiências, seus saberes, e contribui para a efetivação de seus direitos, visando à apropriação das crianças e de seus familiares dos espaços públicos, da cultura do direito, do cotidiano. Conscientes desse papel, poderão se tornar indivíduos transformadores, seres criativos, críticos, cuidantes e capazes de vislumbrar o novo.

\title{
Walter Benjamin, children and social pedagogy: socio-educational experiences developed at the Bompar early childhood education centers
}

\begin{abstract}
Social Pedagogy has systematized libertarian practices that contributed to the constitution of a democratic culture, generating new societal relations. But for that, it is necessary, emancipatory training processes, from birth, which presupposes deconstructing adult-centered conceptions and understanding that babies and children are historical subjects, rights holders, that produce culture and knowledge. Soon, this article reflected part of the socioeducational experiences developed in 18 early childhood education units. The methodological techniques used were analysis of institutional documents and legislation, observation and conversation. The collected data were analyzed from the contributions of Walter Benjamin. One result is the need for social educators to embrace the 'new' that arises in early childhood education, to plan socioeducational, socio-cultural, socio-political, socio-pastoral practices that take into account the different contexts of childhood and drama territories.
\end{abstract}

Keywords: Experience. Social Pedagogy. Walter Benjamin. Bompar. Childhood.

\section{REFERÊNCIAS}

ARIĖS, P. História social da infância e da familia. Tradução Dora Flaksman. Rio de Janeiro: LTC, 1981.

BARROS, M. de. O livro das ignorãças. São Paulo: Record, 1993.

BENJAMIN, W. Reflexões: a criança, o brinquedo, a educação. São Paulo: Summus, 1984.

BENJAMIN, W. Experiência e pobreza. In: BENJAMIN, W. Magia e técnica, arte e política. São Paulo: Brasiliense, 1985. p. 114-119.

BENJAMIN, W. Sobre arte, técnica, linguagem e política. Lisboa: Relógio D'Água, 1992.

BENJAMIN, W. Ensaios reunidos: escritos sobre Goethe. São Paulo: Duas Cidades: Editora 34, 2009.

BENJAMIN, W. O contador de histórias. Reflexões sobre a obra de Nikolai Leskov. In: BENJAMIN, W. Linguagem, tradução, literatura; filosofia, teoria e crítica. Edição e tradução João Barrento. Belo Horizonte: Autêntica, 2013. p. 147-178. 
BISCOLI, I. Â. Atividade lúdica: uma análise da produção acadêmica brasileira no período de 1995 a 2001. 2005. Dissertação (Mestrado em Educação) - Universidade Federal de Santa Catarina, Florianópolis, 2005. Disponivel em: https://repositorio.ufsc.br/handle/123456789/ 103029. Acesso em: 10 maio 2018.

BRASIL. [Constituição (1988)]. Constituição da República Federativa do Brasil de 1988. Brasília, DF: Presidência da República, [2016]. Disponível em: http://www.planalto.gov.br/ccivil_03/Constituicao/Constituiçao.htm. Acesso em: 12 dez. 2020.

BRASIL. Lei n. 8.069, de 13 de julho de 1990. Dispõe sobre o Estatuto da Criança e do Adolescente e dá outras providências. Diário Oficial da União: Brasília, DF, 1990.

BRASIL. Lei n. 9.394, de 20 de dezembro de 1996. Estabelece as diretrizes e bases da educação nacional. Diário Oficial da União: Brasilia, DF, 1996.

BRASIL. Ministério da Educação. Referencial curricular nacional para a educação infantil. Brasilia, DF: MEC/SEF, 1998.

BRASIL. Ministério da Educação. Diretrizes curriculares nacionais para a educação infantil. Brasília, DF: Ministério da Educação, Secretaria de Educação Básica, 2010.

CALIMAN, G. Fundamentos teóricos e metodológicos da Pedagogia Social na Europa (Itália). In: CONGRESSO INTERNACIONAL DE PEDAGOGIA SOCIAL, 1., 2006, São Paulo. Anais [...]. São Paulo: Universidade de São Paulo, 2006. Disponivel em: http://www.proceedings.scielo. Acesso em: 9 maio 2018.

CASTRO, M. G. B. de. Noção de criança e infância: diálogos, reflexões, interlocuções. Niterói: Universidade Federal Fluminense, 2013. Disponivel em: http://alb.com.br/arquivomorto/ edicoes_anteriores/anais16/sem13pdf/sm13ss04_02.pdf. Acesso em: 7 maio 2018.

CENTRO SOCIAL NOSSA SENHORA DO BOM PARTO. Projeto Político Pedagógico Institucional. São Paulo: Bompar, 2009.

CENTRO SOCIAL NOSSA SENHORA DO BOM PARTO. Projeto Político Pedagógico para Educação Infantil. São Paulo: Bompar, 2018.

CENTRO SOCIAL NOSSA SENHORA DO BOM PARTO. Currículo de experiência. São Paulo: Bompar, 2020.

COELHO, D. M. Intervenção em grupo: construindo rodas de conversa. In: ENCONTRO NACIONAL DA ABRAPSO, 14., 2007, Rio de Janeiro. Anais [...]. Rio de Janeiro: Abrapso, 2007.

GRACIANI, M. S. S. Pedagogia social de rua: análise e sistematização de uma experiência vivida. São Paulo: Cortez, 2001.

GRACIANI, M. S. S. Pedagogia social. São Paulo: Cortez, 2014. 
LIMA, M. S. A criança e a cidade. São Paulo: Nobel, 1989.

PEREIRA, A. A educação-pedagogia no cárcere no contexto da Pedagogia Social: definições conceituais e epistemológicas. Revista de Educação Popular, v. 10, p. 38-55, jan./dez. 2011. Disponivel em: http://www.seer.ufu.br/index.php/reveducpop/article/view/20214. Acesso em: 12 maio 2018.

SANTOS, S. E. dos et al. Apresentação do Dossiê: por uma infância descolonizada. Leitura: Teoria \&t Prática, Campinas, v. 31, p. 145-151, 2013. Disponivel em: https://ltp.emnuvens. com.br/Itp/article/download/191/127. Acesso em: 10 maio 2018.

SARMENTO, M. J. As culturas da infância nas encruzilhadas da $2^{a}$ modernidade. Crianças e miúdos: perspectivas sócio-pedagógicas da infância e educação. Porto: Asa, 2004. Disponível em: http://sgmd.nute.ufsc.br/content/especializacao-cultura-digital/educacaoinfantil/medias/files/culturas.pdf. Acesso em: 20 maio 2018.

SARMENTO, M. J. Gerações e alteridade: interrogações a partir da sociologia da infância. Educação \& Sociedade, v. 26, n. 91, p. 361-378, 2005. Disponivel em: https://www.scielo.br/ scielo.php?pid=s0101-73302005000200003\&tscript=sci_arttext. Acesso em: 20 maio 2018.

SILVA, R. da; SOUZA NETO, J. C. de; GRACIANI, M. S. S. (org.). Pedagogia social. São Paulo: Expressão e Arte, 2017.

SILVA, R. da; SOUZA NETO, J. C. de; MOURA, R. (org.). Pedagogia social. São Paulo: Expressão \& Arte, 2009.

SOUZA NETO, J. C. Pedagogia Social: a formação do educador social e seu campo de atuação. Cadernos de Pesquisa em Educação, v. 16, n. 32, p. 29-64, 2010. Disponível em: http://www. periodicos.ufes.br/educacao/article/view/4404. Acesso em: 12 maio 2018.

Recebido em agosto de 2020. Aprovado em novembro de 2020. 